\title{
Reinforcing the Integration Between Researchers of Latin America, North America and Europe in the IHPST Group
}

\author{
Cibelle Celestino Silva • Maria Elice Brzezinski Prestes
}

Published online: 15 March 2012

(C) Springer Science+Business Media B.V. 2012

In Latin America, there are a number of conferences which bring together scholars in history, philosophy and sociology of natural sciences and mathematics, and there are also conferences for science educators. Each of the conferences have specific sections for the relations between both areas, but these separate 'special interest' sections are not enough to create the identity of a community devoted specifically to the overlaps between history, philosophy and sociology of science with science and mathematics education. The First Latin American regional conference of the International History, Philosophy, and Science Teaching Group (IHPST) was the first such conference that brought together the relevant HPS and Science Education groups in Latin America.

For a good number of researchers working in this interdisciplinary field in Latin America Science \& Education is an important and widely read journal. Despite that, few of them publish in it and few attend the biennial meetings of the IHPST Group-because of either language barriers or financial difficulties or both, since the meetings are held in North America and Europe. This picture made urgent the creation of a forum bringing together researchers interested in the overlap between both areas in Latin America.

Thanks to the incentive of IHPST Group we organized the 1st Latin American Conference of International History, Philosophy, and Science Teaching Group (1st IHPST-LA) as a year in between of the international meetings of IHPST Group. The success of the conference in fulfilling this demand was confirmed only by the number of participants and the quality of the presented works, but also by the fact that a second IHPST-LA will take place in Mendoza, Argentina in 2012. Concomitantly to IHPST-LA, the 8th International Conference for the History of Science in Science Education took place in Maresias, Sao Paulo, Brazil in August of 2010, reinforcing the integration and change of experiences between researchers of Latin America, North America and Europe.

C. C. Silva $(\bowtie)$

Institute of Physics of Sao Carlos, University of Sao Paulo, Sao Paulo, Brazil e-mail: cibelle@ifsc.usp.br

M. E. B. Prestes

Biosciences Institute, University of Sao Paulo, Sao Paulo, Brazil

e-mail: eprestes@ib.usp.br 
Both conferences were devoted to presentation and discussion of uses of history, philosophy and sociology of different scientific disciplines such as physics, biology, chemistry and mathematics in education. The papers covered a broad scope of topics and different methodological, epistemological and didactical approaches, reflecting the richness of research developed in the continent and abroad. Since the speakers have different expertise in history, philosophy, sociology and didactics, the conferences contributed to the development and consolidation of this important area for science education in international level, particularly in Latin America.

This special edition of Science \& Education constitutes a small sample of reviewed, revised and accepted presentations from both conferences. Authorship is international: Brazil, Mexico, Canada and Turkey. ${ }^{1}$

Juan Manuel Sánchez Arteaga and Charbel Niño El-Hani examine the scientific discourse on interracial competition and racial extinction as an example to promote teaching of science-technology-society (STS) aspects. The paper has two parts; the first one discusses the ideology behind the concepts of interracial competition and racial extinction used in the evolutionary biology at the end of nineteenth century. They review the episode showing that during this period the scientific community considered that native populations were extinct or at verge of extinction due to a competition with Caucasians regarded as evolutionary superior. In this episode, biological sciences provided a scientific legitimation for imperialist and racist policies. In the second part, the authors discuss a series of design principles for building teaching sequences about scientific racism and STS issues, articulating scientific principles with cultural and anthropological ones. This case study can be used as a critical platform to students and science teachers discuss the presence of ideological content in the present day biomedical technosciences. By the study of this episode students can be conscious about othering practices and, thus, be able to understand contemporary cases of racism in more critical light.

The contribution of Maria Teresa Guerra-Ramos analyzes research designed to elicit teachers' views on nature of science. She focuses on the conceptual basis inherent in different methodological approaches reveling four categories to classify the researchers' views of teachers' knowledge. The paper points some pitfalls faced by methodologies that do not consider pedagogical aspects, such as the assumption that teachers understanding about science is stable and that it matches perspectives of current philosophy, history and sociology of science; little can be concluded about pedagogical implications if they are not explored in real teaching situations and connected to scientific content; the fact that there are almost none studies that consider the connections between teachers' thinking and the actual demands they face in the classroom. In her paper Guerra-Ramos brings a light to the studies about teachers' views on NOS and proposes new perspectives for research.

The following two papers address obstacles existing for inclusion of HPS in classrooms using different and complementary approaches. Thaís Cyrino de Mello Forato, Roberto de Andrade Martins and Mauricio Pietrocola report results of an empirical study carried on in a Brazilian secondary public school. The research includes the elaboration and application of a course on history of optics addressing nature of science aspects. The activities were designed in partnership between one of the researchers and the school teacher. In the course students used primary and secondary sources in activities planned considering both pedagogical and historiographical requirements. Along the course, the obstacles present in literature were identified by both who re-designed the activities in order to overcome and

\footnotetext{
${ }_{1}$ Other papers from both conferences can be found by Silva and Prestes (in print).
} 
compensate such obstacles. The authors generalize their results suggesting parameters that can be used by science teachers while including HPS in their practice.

Hayati Seker and Burcu G. Guney examines alignments between history of science and curriculum using the Facilitator Model developed by them in order to identify obstacles to the integration of history of science into Turkish physics curriculum and into instructional material. The facilitator model proposes the existence of four contexts for the use of history of science in classrooms: interest level, sociocultural level, epistemological level, and conceptual level. The levels of the model consider teachers' competence in using history of science in their teaching and are illustrated by simple historical examples taken from history of mechanics and electricity.

Karina Aparecida F. D. Souza and Paulo Alves Porto developed an empirical work devoted to the analysis of a representative sample of textbooks for chemistry higher education in Brazil throughout the twentieth century. The authors used as methodology for the present study iconographical and textual analysis of these materials, considering the context of their production, the academic background, and beliefs of their authors. As a result it emerged a history of chemical education in the country. This history was traced in close relation with commitments to three successive different conceptions of chemistry along the century: chemistry as an experimental science, as a science of the invisible, as a science of interfaces and of undeniable technological influence. The research shows some of the historical changes in curriculum, in teaching approaches and in epistemological aspects of chemistry. Thus, the paper content can promote a critical and analytical orientation for teaching chemistry in a contextualized way.

Also dealing with instructional materials, Stephen Klassen, Mansoor Niaz, Don Metz, Barbara McMillan and Sarah Dietrich analyzed laboratory manuals for the photoelectric effect for undergraduate students on physics from pedagogical perspective. This physical effect began to be included in undergraduate student laboratories in the 1960s, although it was accepted by physic community at the time of 1927 Solvay Conference. Apparatus for teaching the effect started to be widely used by the 1970s after developments of solid-state electronics and changes in the method originally used by Millikan in order to make the apparatus easier to use and adjust. The present paper briefly discusses some of practical aspects involved in making the apparatus more convenient to classrooms. The focus of the study is how historical underpinnings of the photoelectric effect are portrayed in these lab manuals. The criteria for evaluating the manuals are based on historical reconstruction of the photoelectric effect and consider historical and philosophical aspects. As result, none of the manuals were considered excellent and, in general, they ignore the historical context and experimental data that can led to alternative interpretations of the effect. The authors strongly suggest the use of historical approach to deal with the difficulties of conceptual understanding of the photoelectric effect, which is not facilitated in laboratory investigations.

José A. Chamizo presents results of activities with Mexican master degree students using heuristic diagrams for helping them to construct a meaningful approach to chemistry's history. The diagram is an improvement of Bob Gowin's Vee heuristic, modified with Stephen Toulmin's philosophical approach and his idea that problems and problemsolving are central to scientific activity. It allows students to investigate the evolution of concepts by answering a particular question. According to the author, the heuristic diagram helped students to create meanings to their historical research projects, to learn to be successful problem solvers, and improved their ideas about science and their competence to teach about history of science. Besides the students, teachers gain with the use of 
heuristic diagrams. Its application in history of science courses demands a change in the role of teachers, from the usual instruction-oriented role to a more guidance-oriented role.

We are thankful to Michael Matthews who offered us the opportunity to edit this special issue of Science \& Education. We are also grateful to the support of University of São Paulo, São Paulo State Research Foundation (FAPESP), Ministry of Education by the Coordination for the Improvement of Higher Level Personnel (CAPES), International History, Philosophy, and Science Teaching Group (IHPST), Springer Publishing, the Teaching Commission of the Division of History of Science and Technology belonging to International Union of History and Philosophy of Science, and also the journal Science \& Education.

\section{Reference}

Silva, C. C., \& Prestes, M. E. B. (Eds.) (in print). Learning science and about science through history and philosophy. Sao Paulo: Livraria da Física. 